\title{
Entrance Security Based Barcode and RFID System
}

\author{
Manoj Kumar Ojha
}

\begin{abstract}
This paper discourses about a very general problem that occurs in everyday life. In many universities, students are at risk of misplacement or theft of valuables. So, to avoid such mis happening, the development of security system was designed for providing the safety of university student belongings. The proposed security system contains some common information, methodology, schematics and some details related to technical field that is employed into the system, such as RFID (Radio Frequency Identification) and barcode readers along with the design of the established system. For the functioning of the system in a most effectively manner, assumptions with some specific requirements that is needed to be met are encompassed in this paper.
\end{abstract}

Keywords- Lab security, barcode, RFID, security system, microcontroller.

\section{INTRODUCTION}

The definition of "Internet of Things (IoT) could be given as a global infrastructure that combines intelligent services with situational awareness and lets interactive communication in between one entity and the other, also between sharp and people objects within a system" [1]. The communication of Machine to Machine is comparatively much dissimilar than the use of IOT since nobody is controlling the apparatus or equipment tool directly. The internet of things is generally controlled by the group of persons. At present, a variety of choice has been reviewed in the matter of the communication machineries for getting a proposal fact about matters. IoT technology can now communicate with a combination of appliances for home devices and mobile devices. Recently, "electronic door locks" are used in several homes and administration offices [2], [3]. In many situations, by circumventing the lock, an intruder has attempted to penetrate an area. In many situations, the interloper tried to break into the area by avoiding the lock. In this research, door locks are designed and adopted to improve various security using barcode scanning and RFID technology and minimizes the rate of damaging of digital door lock interfering.

Developed models comes into the class of "Electronic Article Surveillance (EAS)" [4], using special tags fixed to goods or books. At the store exit, when the active tag gets detected, the detecting system alerts the supervisor by making an alarm sound. Likewise, in the present paper, RFID tags are fixed to the monitored item, the reader module will detect some object, and the detected data gets compared by a microcontroller which after comparison aids in producing an alarm. In many cases, students are at risk of misplacement and theft of valuables and other personal

Revised Manuscript Received on 14 September, 2019.

Manoj Kumar Ojha, Department of Electronics Engineering, Sanskriti University, Uttar Pradesh, India.(Email: sanpubip@gmail.com) items [5], [6]. On the basis to a Tech Crunch report, united state countries on an average lost their one mobile phone each year, causing $\$ 30$ billion of money lost in 2012. Due to the theft of personal wallets, a person can lose their driver's license, cash and credit card. It is not so easy in general to mention the theft in high grade collages.

Therefore, for minimizing the above problems related to security, the security system is planned and developed that is capable of providing the safety to the university students of their personal properties. Recently, numerous ranges of alarm have been developed that uses different technologies some of them are radio frequency identification, GPS, twodimension Barcodes, Wireless sensors, etc. [7]-[9]. Current work is integrating RFID and barcode technology to recommend a low cost and most effective security system for students.

\section{DESCRIPTION OF MECHANISMS}

\section{A. Radio frequency identification (RFID)-}

For the automatic detection or identification of any object such as any person or vehicle, RFID plays a dominant role in such cases. RFID is a broad terminology describing the use of radio waves for transmitting a unique serial code in a form of number after detecting a person or any other object wirelessly [9]. Likewise, the barcode, the application of RFID does not need any line of sight or contact for the purpose of communication. The information of the RFID is readable by a means of any person, clothes or any other materials that are not metallic. Basically, an RFID comprises of 3 parts i.e. a coil acting as antenna, transceiver and thirdly RF tag that includes unique info.

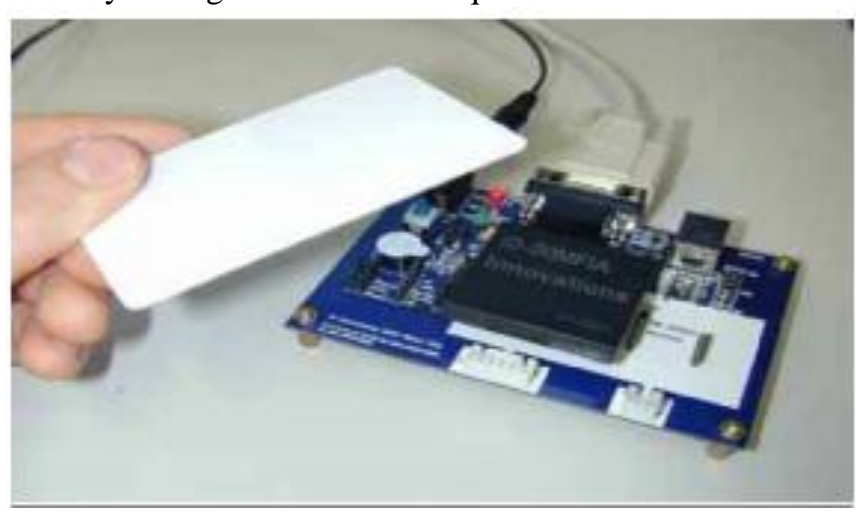

Fig.1 RFID Module

\section{B. Barcode-}

"A barcode is an optical machine-readable representation of data relating to the object to which it is attached" [10].

\section{Published By:}

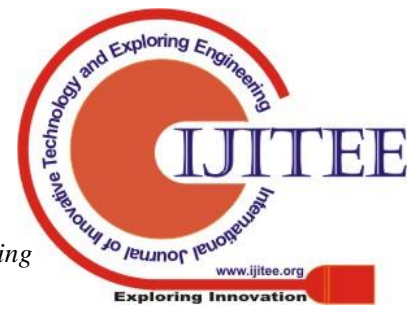


Formerly, the barcodes analytically signify information through adjusting the thicknesses and space of parallel lines arrangement, it could be denoted as one dimensional or linear. For the purpose of scanning these barcodes, a visual scanner is introduced and originally named as barcode reader. The barcode readers can be found in various applications such as reading the product information that is printed in wrappers or outer cover of any products and goods. Moreover, almost each and every barcode scanner encompass a decoding circuit board that determines the data image of barcode.

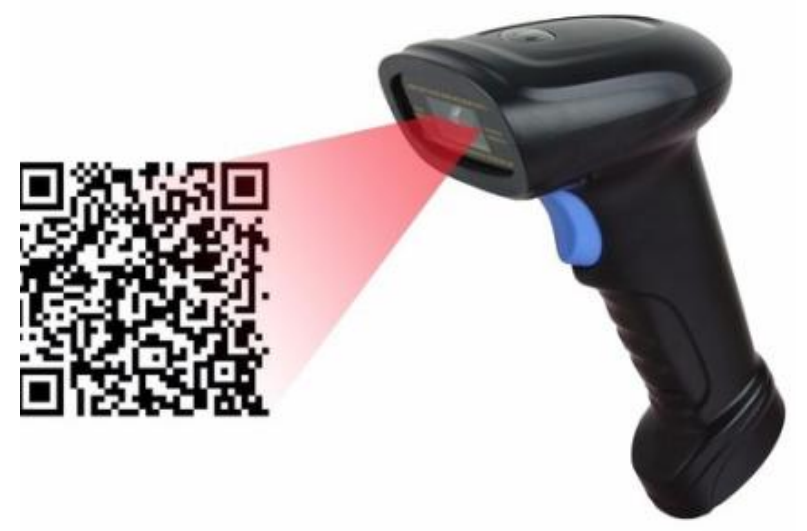

Fig.2 Barcode reader

The fig. 3 shows the procedure of proposed system in the form of block diagram. The system is basically sub-divided into 3 portions- first is the RFID unit that enclosure the specifications of student properties, things and stuff, second is the Barcode sector that is employed for obtaining student identification, and lastly is the microcontroller unit that is implemented basically for comparing the data of RFID and barcode and generates the alarm signal accordingly.

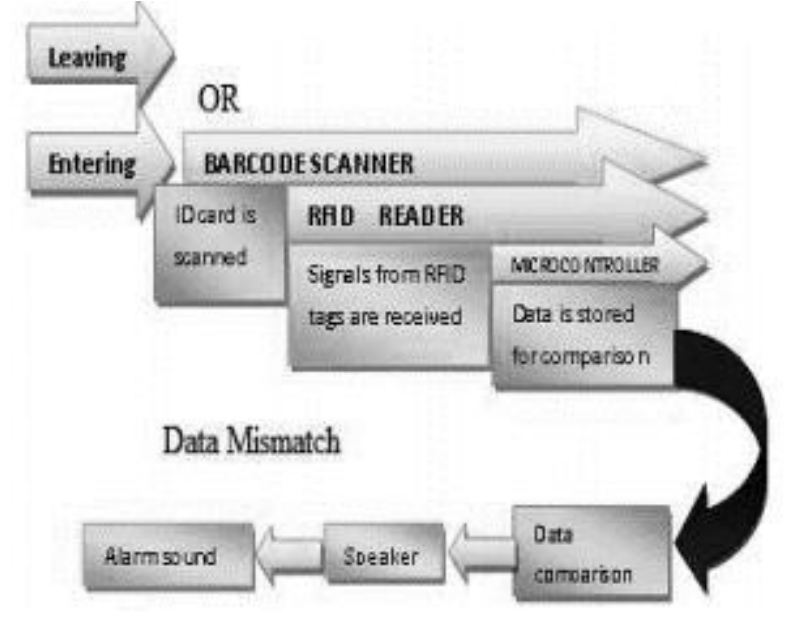

Fig.3 Block diagram of proposed system

\section{WORKING}

During the entrance of any person, student or scholar inside any offices, laboratories etc. the ID card which is provided to each of the student comprises barcode in it that is scanned by the barcode reader due to which a unique number of each student is stored. All the important stuffs of students such as mobiles, wallets, fountain pen, scientific calculators etc. encompass an RFID tags that is capable of storing the holder's WSN. The tags that are placed in the student's belongings are non-removable and nonreplaceable. As the students or scholars do entry or exit the classroom, office or laboratory, the reader namely the RFID that is fitted on the door will scan the data tag placed on each belonging of a particulars [12]. Mutually the RFID reader and the barcode scanner both are associated to the microcontroller. The microcontroller is used to compare the data of each student during the entry or exist from laboratory or any other place. If the stuff persuaded by the particular students is found to be their own, then a microcontroller will generate the command signal to the green light to glow. If the stuff is not match with the particular student then microcontroller will generate an alarm signal and a red light will glow.

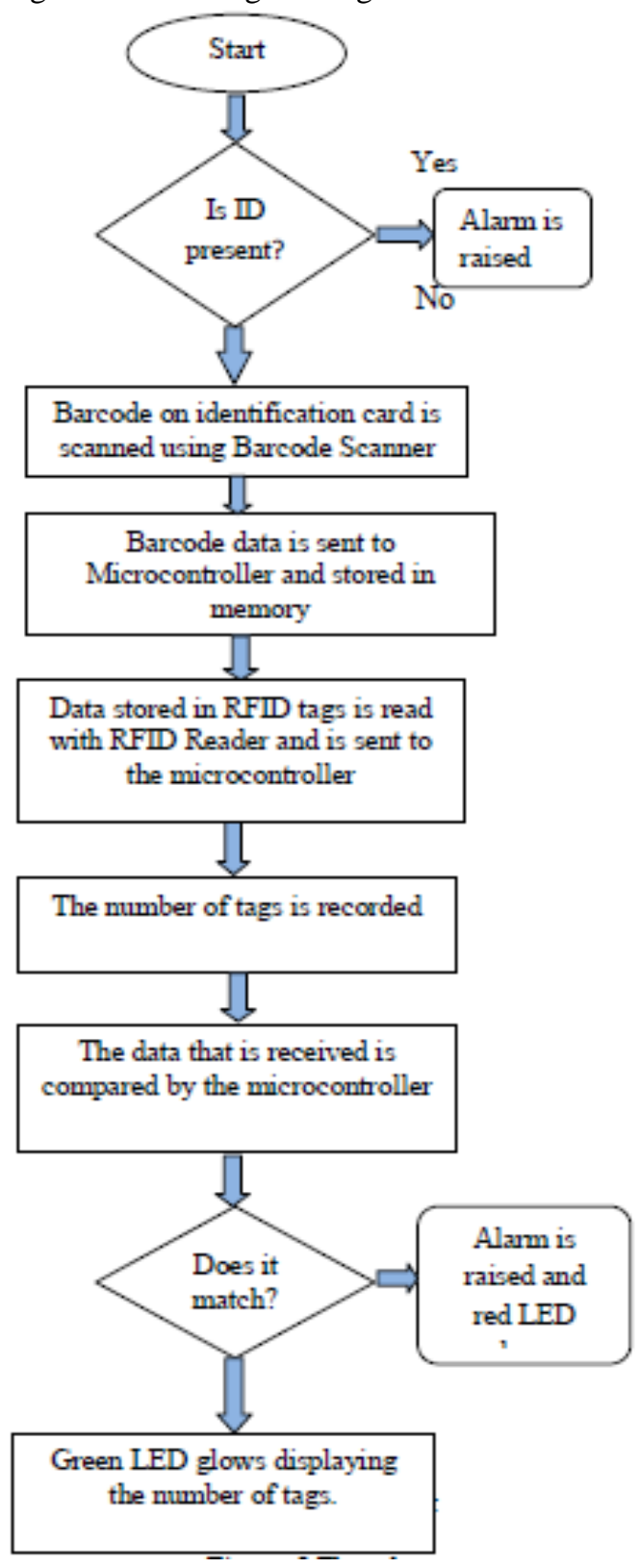

Fig.4 Flow diagram of proposed system 


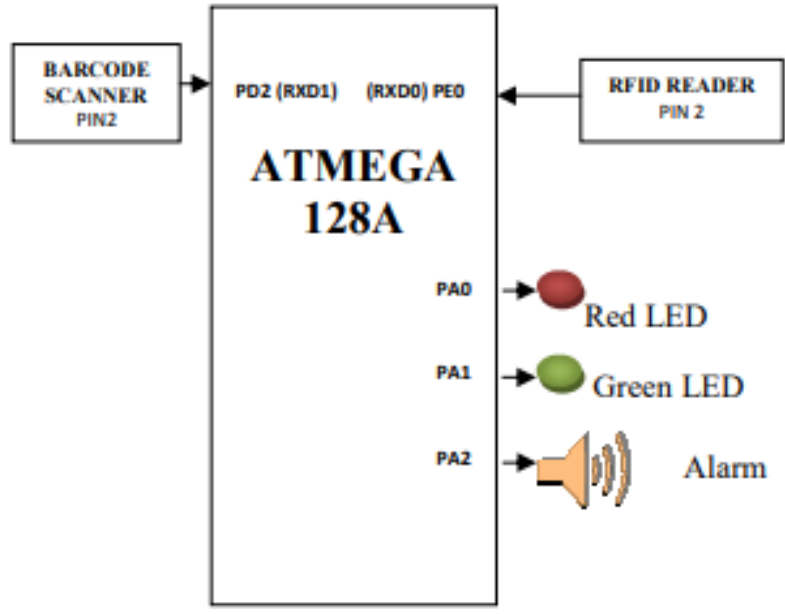

Fig.5 Connection of components in proposed system

\section{RESULT AND CONCLUSION}

The designing of Entrance Security Based Barcode and RFID System is done successfully. This system eliminates the various problems related to the theft of the student or scholar personal belongings and stuff. The RFID and barcode system give safety to the school, collages etc. from thief. The incorporation of both RFID and Barcodes is cost effective solution for all. RFID tags cannot completely replace barcodes. This has the added advantage of being expensive and having multiple data sources on the same object. As such, RFID tags are often a complement to UPC or EAN barcodes, but not a replacement. RFID advocates see RFID as a successor to optical bar codes that are often printed on consumer products, and have two separate merits.

\section{REFERENCES}

1. L. Da Xu, W. He, and S. Li, "Internet of things in industries: A survey," IEEE Transactions on Industrial Informatics. 2014.

2. B. Zhang, K. Ren, G. Xing, X. Fu, and C. Wang, "SBVLC: Secure barcode-based visible light communication for smartphones," IEEE Trans. Mob. Comput., 2016.

3. Y. C. Lin, W. F. Cheung, and F. C. Siao, "Developing mobile 2D barcode/RFID-based maintenance management system," Autom. Constr., 2014.

4. L. Guo, J. Duan, J. Li, L. Yu, and H. Shen, "HAS: Hidden anti-theft system based on wireless sensor networks," in 2012 IEEE 31st International Performance Computing and Communications Conference, IPCCC 2012, 2012.

5. Y. Han, Z. Chen, and T. Guo, "Design of equipment antitheft tracker based on wireless sensor network," in 1st International Conference on Electronics Instrumentation and Information Systems, EIIS 2017, 2018, vol. 2018January, pp. 1-5.

6. H. Zhang, F. Zhang, Y. Wang, and G. Zhang, "Wireless Sensor Network based anti-theft system of monitoring on petroleum pipeline," in 2011 2nd International Conference on Mechanic Automation and Control Engineering, MACE 2011 - Proceedings, 2011, pp. 4689-4692.

7. "Bank Locker Security System based on RFID and GSM Technology," 2012.

8. A. Ramzan, S. Rehman, and A. Perwaiz, "RFID technology: Beyond cash-based methods in vending machine," in 2017 2nd International Conference on Control and Robotics Engineering, ICCRE 2017, 2017.
9. S. H. J. S. S. Agrawal, "Smart Bank Locker Security System Using Biometric Fingerprint and GSM Technology,” Int. J. Sci. Res., 2016.

10. A. Akbari, S. Mirshahi, and M. Hashemipour, "Comparison of RFID system and barcode reader for manufacturing processes," in Canadian Conference on Electrical and Computer Engineering, 2015. 